\title{
Research on Decision-making Behavior Evolution of Government, Coal Mine Enterprises and Employees under Safe Education
}

\author{
Yun Teng ${ }^{1}$, Yan-Qi Wang ${ }^{1 *}$, Jia-Li Wang ${ }^{1}$, Li-Li Zhang ${ }^{1}$ \\ ${ }^{1}$ Northeast Agricultural University, CHINA
}

Received 12 June 2017 • Revised 24 October 2017 • Accepted 10 November 2017

\begin{abstract}
The penalty type education mode for safety production is lack of systematic and comprehensive education thought, education system and education measures, which leads to frequent safety accidents. To promote the safety education level of China's coal mining enterprises, in this study, the government, coal mine enterprises and employees are included in the evolutionary game model to explore the game relation and evolutionary path of the decision-making behavior among the three stakeholders in the safety management and education. It is proved by decision-making dynamic replication analysis, strategy evolution stability analysis and numerical simulated experiment verification that: the decision-making behavior of the government, coal mine enterprises and employees is the result of the mutual game playing among the three stakeholders. It is impossible for the government to leave alone the enterprises adopting the penalty type education mode for safety production. The incentive type education mode for safety production takes active education thought, education system, education measures and so on. It has become an effective driving factor to promote safety education level and motivate employees' safety initiative. When certain conditions are met, the decision-making behavior of three stakeholders of the government, coal mine enterprises and employees can evolve into an ideal state. The evolution process of decision-making behavior of three stakeholders to the ideal state is influenced by many factors. The range of different factors has a differential effect on the convergence rate of the three stakeholders to the ideal state.
\end{abstract}

Keywords: safety education, education mode, game evolution, decision-making behavior

\section{INTRODUCTION}

Although safety education have been improved constantly, safety production accidents are important problems that governments all over the world have to face and deal with (Jiang et al., 2010; Kumar et al., 2016). According to the World Health Organization (WHO) statistics, the economic losses caused by safety accidents account for about $4 \%$ to $5 \%$ of global GDP (Krzemień et al., 2016; Perdomo-Diaz et al., 2017). Safety accidents not only cause economic losses, but also have a negative impact on social stability. It is stressed in 2014-2016 Chinese government work report that "there is nothing more important than human life. Attentions must be paid to safety at all times during production". The government should strictly enforce the laws and supervisions on safety in production, fully implement the responsibility institution for safety in production, and strengthen safety education and training. Enterprise safety education should be based on the background of building a harmonious society, take scientific outlook on development as the basic guiding ideology, and take the essential security as the concept (Wang et al., 2016; Wei et al., 2015; Torres et al., 2017). Under the support of Marx's theory and other related scientific theory system, the changes and characteristics of employees' security psychology during the transition period are explored, so as to curb the occurrence of heavy and serious accidents (Liu et al., 2015). Therefore, safety education has become an important factor to improve the level of safety in production and stabilize the society.

(C) Authors. Terms and conditions of Creative Commons Attribution 4.0 International (CC BY 4.0) apply. 《809114339@qq.com $\boldsymbol{\Delta}$ dingding212139@163.com (*Correspondence) $\square$ 76549223@qq.com 凶84767947@qq.com 


\section{Contribution of this paper to the literature}

- The paper demonstrated that the decision-making behaviors are the outcomes of the game among the three stakeholders under the background of safety education.

- The paper concluded that the cost of government supervision, penalty, supervision efficiency, enterprise and government cooperation, mode transformation costs, positive or negative psychological effect from employee safety initiative behavior are crucial factors to achieve the ideal decision-making of stakeholders.

- The paper provided theoretical reference and practical guidance for the government to formulate safety supervision decision-making, enterprise safety education mode transformation and employee safety initiative motivation.

Coal mine enterprises belong to high-risk industries. Because of the particularity of production environment, the variability and unpredictable nature of natural conditions, the accident rate is much higher than other industries. Therefore, the safety production of coal mine enterprises has been highly concerned by the party and the government (Zhang et al., 2012; Chen et al., 2013; Zhang et al., 2016). China's coal output accounts for about $33 \%$ of the world's total coal output, while the death toll from the mine accident accounts for about $80 \%$ of the world mine fatalities (Chen et al., 2015). In recent years, the Chinese government and enterprises have gradually realized that the education mode for safety production plays a key role in safety production activities, the education mode for safety production determines the safety production management situation; the traditional penalty type education mode for safety production is limited by supervisions and strict punishment, and lacks advanced education thoughts, education methods and education means, which results in the failure to motivate employees to work safety (Cao et al., 2012). The foreign education mode for safety production is transformed from penalty type to incentive type, which can provide reference for Chinese coal mine enterprises. The Chinese government requires coal mine enterprises to carry out the transformation of education mode for safety production, for example, Shenhua Group, Xuzhou Mining Group, Lu'an Energy Company, Kailuan Group and other enterprises (Feng and Chen, 2013). The incentive type education mode for safety production refers to the higher level education mode for safety production which gives full play to human initiative, in which the organization following the education concept that guides people's behavior, uses the education method that can increase people's safety knowledge and consciousness, and arouse people's initiative behavior to formulate incentive education institution to carry out safety production activities (Fernández-Muñiz et al., 2007), this mode is designed to mobilize the initiative of employees in safety production. Research and analysis on coal mine enterprises as the stakeholders of safety education decision-making behavior can promote enterprises to carry out safety in production. The implementation of effective safety education will help enterprises to realize the transformation of education mode for safety production.

The infiltration of human centered education has made scholars realize that human beings are one of the main subjects of safety education activities. The education mode for safety production should develop in the humancentered direction. The incentive type education mode should be transformed into the mode stimulating active education (Vinodkumar et al., 2011; McDonald et al., 2000; Pousette et al., 2008). Human behavior is a direct factor in determining safety performance. Human's safety behavior can be divided into safety passive behavior and safety initiative behavior (Aryee and Hsiun, 2016; Smith et al., 2016). Safety initiative behavior refers to the behavior of individual in the safety production activities, which is beyond the statement of clearly defined job description and job responsibility, and has a positive impact on organizational safety effectiveness (Neal et al., 2000; Chin et al., 2010). They will take the initiative to learn safety knowledge, advice and help behavior. The existing literature shows that the safety initiative is negatively related to the safety accident rate, which is, the more employees' safety initiative, the higher the rate of safety accidents avoided is (De Armonda et al., 2011). However, domestic researchers pay more attention to the study of safety initiative behavior, but ignore safety passive behavior. Safety initiative belongs to the voluntary initiative behavior outside the enterprise, and becomes an important factor to improve the safety performance of the enterprise. Thus, employee safety initiative behavior is selected as the research object in this paper (Zhang et al., 2012; Chen et al., 2013; Martin-Gutierrez, 2017). Evolutionary game theory has been introduced into the field of coal mine safety education Only stay at the evolutionary analysis on game between both sides of enterprise safety education decision-making (Liu and Li, 2015; Wang et al., 2016; Liu et al., 2015). In view of the fact that the three stakeholders of government, enterprises and employees in the coal mine safety production have incomplete information and limited rationality, a dynamic evolutionary game model of 2 * $2 * 2$ is constructed, to reveal the evolution path and evolution law of decision-making behavior of government, coal mine enterprises and employees in safety education, and find out the stability condition of the three stakeholders to reach the ideal state, in order to provide useful suggestions for the government to formulate safety regulatory decisions, to transform the education mode of enterprise safety production and to motivate employees' safety initiative. 
Table 1. Income portfolio of evolutionary game of three parties

\begin{tabular}{|c|c|c|c|}
\hline strategy portfolio & government benefits & coal mine enterprise benefits & employee benefits \\
\hline $\begin{array}{l}\text { (safety supervision, incentive } \\
\text { education type, implemented) }\end{array}$ & $-C_{1}+W$ & $-C_{2}+S+a_{1}\left(1-B_{1}\right) L+F$ & $a_{1} B_{1} L+A_{1}+T$ \\
\hline $\begin{array}{l}\text { (safety supervision, incentive type, } \\
\text { not implemented) }\end{array}$ & $-C_{1}+W$ & $-C_{2}+S$ & $T$ \\
\hline $\begin{array}{l}\text { (safety supervision, penalty education } \\
\text { type, implemented) }\end{array}$ & $-C_{1}-V+W+M$ & $-M+a_{2}\left(1-B_{2}\right) L+F$ & $a_{2} B_{2} L-A_{2}+T-R$ \\
\hline $\begin{array}{l}\text { (safety supervision, incentive } \\
\text { education type, not implemented) }\end{array}$ & $-C_{1}-V+W+M$ & $-M$ & $T-R$ \\
\hline $\begin{array}{l}\text { (unsafe supervision, incentive } \\
\text { education type, implemented) }\end{array}$ & 0 & $-C_{2}+S+a_{1}\left(1-B_{1}\right) L+F$ & $a_{1} B_{1} L+A_{1}$ \\
\hline $\begin{array}{l}\text { (unsafe supervision, incentive } \\
\text { education type, not implemented) }\end{array}$ & 0 & $-C_{2}+S$ & 0 \\
\hline $\begin{array}{l}\text { (unsafe supervision, penalty } \\
\text { education type, implemented) }\end{array}$ & $-V$ & $a_{2}\left(1-B_{2}\right) L+F$ & $a_{2} B_{2} L-A_{2}-R$ \\
\hline $\begin{array}{l}\text { (unsafe supervision, penalty } \\
\text { education type, not implemented) }\end{array}$ & $-V$ & 0 & $-R$ \\
\hline
\end{tabular}

\section{HYPOTHESIS PROPOSING AND MODEL BUILDING}

The government, coal mine enterprises and employees are incorporated into a game system, and the three stakeholders have limited rationality and learning imitation ability. Considering the factors of safety supervision cost, reducing enterprise safety production accidents and social stability, the government chooses safety supervision or unsafe supervision strategies. In consideration of the factors of government deterrence, transformation cost, safety income and so on, the coal mine enterprises choose the penalty type education mode for safety production or the incentive type education mode for safety production strategy. Taking into account the benefits of their own, employees choose to implement safety initiative behavior or do not implement safety initiative behavior strategy. Profit and loss analysis is as follows:

The related gains and losses of the government: When the safety monitoring decision is taken, the safety monitoring cost is $C_{1}$. The adverse effect borne by the government as a result of the enterprise's adopting the penalty type education mode for safety production is $V$. Government security monitoring good for social stability is $W$. At the same time, the fine paid by the enterprise without the transformation of the education mode for safety production is $M$. When the government adopts unsafe monitoring decisions, the effect on the revenue by the enterprise strategy is 0 or $-V$.

The related gains and losses of the coal mine enterprises: If enterprises adopt the incentive type education mode for safety production, additional transformation costs such as enterprise safety education, safety culture and security incentives to be paid are $C_{2}$. Because the enterprise adopts the incentive type education mode for safety production .government financial support, bank loans and other preferential opportunity costs that may be obtained are $S$. Safety benefits of employee safety initiatives behavior is $a_{1}\left(1-B_{1}\right) L$. The positive psychological impact of employee safety initiative behavior on other employees is $F$. If the enterprises adopt the penalty type safe mode for production management, the impact of employee strategy on the benefits is one of $0, M, a_{2}\left(1-B_{2}\right) L+F$ or $-M+a_{2}\left(1-B_{2}\right) L+F$.

The related gains and losses of the employees: The positive impact of government safety supervision behavior on employees is $T$. The negative effects of enterprise penalty type education mode for safety production on employees is $R$. When the amount of labor of employees' safety initiative behavior is $L$, there are two situations: (1) In the incentive type education mode for safety production, the input-output ratio of safety initiative behavior is $1 / a_{1}$; the safety benefit ratio of employees' safety initiative behavior is $B_{1}$; safety benefit of employees is $a_{1} B_{1} L$. The positive psychological effect on employees from the incentive type education mode for safety production encouraging the safety initiative of employees, such as public praise, setting up as a safety mode is $A_{1}$; and the positive impact of employee safety initiative on other employees is $F$.(2) Under the penalty type education mode for safety production, the input-output ratio of safety initiative behavior is $1 / a_{2}$; the safety benefit ratio of employees' safety initiative behavior is $B_{2}$; safety benefit of employees is $a_{2} B_{2} L$. The negative psychological effect on employees from the penalty type management for safety production because of its lack of attention, encouragement, education and so on to the safety initiatives of employees is $A_{2}$.

According to the content, we can get income matrix of the portfolio of 8 strategies. The contents are shown in Table 1. 
In the above relations, according to the actual situation, the restriction conditions that may be increased: Compared to the penalty type education mode for safety production, in incentive type education mode for safety production, employees' safety income and output is relatively high, and the safety benefit ratio of employees' safety initiative behavior is relatively high, that is, $a_{1}>a_{2}, B_{1}>B_{2}$. In the case of the same amount of labor in safe production, the safety benefits obtained under the incentive type education mode for safety production are greater than those obtained in the penalty type education mode for safety production, that is, $a_{1}\left(1-B_{1}\right) L>a_{2}\left(1-B_{2}\right) L$.

\section{EQUILIBRIUM ANALYSIS ON EVOLUTIONARY GAME}

Supposing that in the initial stage of the game, the proportion of governments taking safety supervision strategy is $x$, the proportion of governments not taking safety supervision strategy is $1-x$; the proportion of coal mining enterprises taking incentive type education mode for safety production is $y$, that taking penalty type education mode for safety production is $1-y$; the proportion of employees taking safety initiative behavior is $z$, the proportion of employees not taking safety initiative is $1-z$.

(1) The expected revenue of "supervision" and "non-supervision" decisions of government groups are $V_{1 X}$ and $V_{2 X}$, and the average revenue is $\overline{V_{X}}$

$$
\begin{gathered}
V_{1 X}=y z\left(-C_{1}+W\right)+y(1-z)\left(-C_{1}+W\right)+.(1-y) z\left(-C_{1}-V+W+M\right)+(1-y)(1 \\
-z)\left(-C_{1}-V+W+M\right) \\
V_{2 X}=(1-y) z(-V)+(1-y)(1-z)(-V) \\
\overline{V_{X}}=x y\left(-C_{1}+W\right)+x(q-y)\left(-C_{1}+M-V+W\right)+(1-x)(1-y) z(-V)+(1-x)(1 \\
-y)(1-z)(-V)
\end{gathered}
$$

(2) The expected revenue of "penalty type" and "incentive type" education mode for safety production of coal mining enterprise group are $V_{1 Y}$ and $V_{2 Y}$, and the average revenue is $\overline{V_{Y}}$

$$
\begin{aligned}
& V_{1 Y}=x z\left[-C_{2}+S+\left(1-B_{1}\right) a_{1} L+F\right]+x(1-z)\left(-C_{2}+S\right) \\
& +(1-x) z\left[-C_{2}+S+a_{1}\left(1-B_{1}\right) L+F\right]+(1-x)(1-z)\left(-C_{2}+S\right) \\
& V_{2 Y}=x z\left[-M+a_{2}\left(1-B_{2}\right) L+F\right]-M x(1-z)+(1-x) z\left[a_{2}\left(1-B_{2}\right) L+F\right] \\
& \overline{V_{Y}}=y\left(-C_{2}+S\right)+y z\left[\left(1-B_{1}\right) a_{1} L+F\right]-M x(1-y) z+x(1-y)(1-z)(-M) \\
& +(1-y) z\left[a_{2}\left(1-B_{2}\right) L+F\right]
\end{aligned}
$$

(3) The expected revenue of "implementing safety initiative" and "not implementing safety initiative" decisions of employees are $V_{1 Z}$ and $V_{2 Z}$, and the average revenue is $\overline{V_{Z}}$

$$
\begin{gathered}
V_{1 Z}=x y\left[a_{1} B_{1} L+A_{1}+T\right]+x(1-y)\left(a_{2} B_{2} L-A_{2}+T-R\right)+(1-x) y\left[a_{1} B_{1} L+A_{1}\right]+(1 \\
-x)(1-y)\left(a_{2} B_{2} L-A_{2}-R\right) \\
V_{2 Z}=x y T+x(1-y)(T-R)+(1-x)(1-y)(-R) \\
\overline{V_{Z}}=x T+y z\left(a_{1} B_{1} L+A_{1}\right)+(1-y)\left[z\left(a_{2} B_{2} L-A_{2}\right)+(-R)\right]
\end{gathered}
$$

\section{Dynamic Replication Analysis on Government Safety Regulatory Decision-Making}

The dynamic replication equation of government safety supervision and decision:

$$
F(x)=\frac{d x}{d t}=x\left(V_{1 X}-\overline{V_{X}}\right)=x(x-1)\left[y M-\left(M-C_{1}+W\right)\right]
$$

(1) When $y=\frac{M-C_{1}+W}{M}, F(x)^{o} 0$, this means that the government is in a steady state by taking any proportion of safety supervision.

(2) When $y^{1} \frac{M-C_{1}+W}{M}$, let $F(x)=0$, then $x=0, x=1$ may be the evolutionary stability points. According to the stability theorem of replicated dynamic equation, if $x$ is a stabilization strategy, then $F(x)=0$ and $F^{\prime}(x)<0$.

By deriving $F(x)$ :

$$
F^{\prime}(x)=(2 x-1)\left[y M-\left(M-C_{1}+W\right)\right]
$$

Under normal circumstances, $M>C_{1}$, there are two cases:

When $y>\frac{M-C_{1}+W}{M}$ 时, $\left.\frac{d F(x)}{d x}\right|_{x=1}<0,\left.\frac{d F(x)}{d x}\right|_{x=0}>0$, so $x=1$ is the evolutionary stability point.

When $y>\frac{M-C_{1}+W}{M}$ 时, $\left.\frac{d F(x)}{d x}\right|_{x=1}>0,\left.\frac{d F(x)}{d x}\right|_{x=0}<0$, so $x=0$ is the evolutionary stability point. 


\section{Dynamic Replication Analysis on the Decision-Making of Incentive Type Education Mode for Safety Production in Coal Mining Enterprises}

The dynamic replication equation of the decision-making of incentive type education mode for safety production in coal mining enterprises:

$$
F(y)=\frac{d y}{d t}=y\left(V_{1 y}-\overline{V_{y}}\right)=y(1-y)\left\{z\left[a_{1}\left(1-B_{1}\right) L-a_{2}\left(1-B_{2}\right) L\right]-\left(C_{2}-S-M x\right)\right\}
$$

(1) When $z=\frac{C_{2}-S-M x}{a_{1}\left(1-B_{1}\right) L-a_{2}\left(1-B_{2}\right) L}, F(y)^{o} 0$, this means that the coal mining enterprise is in a steady state by taking any education mode for safety production.

(2) When $z^{1} \frac{C_{2}-S-M x}{a_{1}\left(1-B_{1}\right) L-a_{2}\left(1-B_{2}\right)}$, let $F(y)=0, y=0, y=1$ may be the evolutionary stability points. According to the stability theorem of replicated dynamic equation, if $y$ is a stabilization strategy, then $F(y)=0$ and $F^{\prime}(y)<0$. By deriving $F(y)$ :

$$
F^{\prime}(y)=(1-2 y)\left\{z\left[a_{!}\left(1-B_{1}\right) L-a_{2}\left(1-B_{2}\right) L\right]-\left(C_{2}+S-M x\right)\right\}
$$

Under normal circumstances, $a_{1}\left(1-B_{1}\right) L>a_{2}\left(1-B_{2}\right) L$, there are two cases:

When $z>\left.\frac{C_{2}+S-M x}{a_{1}\left(1-B_{1}\right) L-a_{2}\left(1-B_{2}\right) L^{\prime}} \frac{d F(y)}{d y}\right|_{y=1}<0,\left.\frac{d F(y)}{d y}\right|_{y=0}>0$, so $y=1$ is the evolutionary stability point.

$z<\left.\frac{C_{2}+S-M x}{a_{1}\left(1-B_{1}\right) L-a_{2}\left(1-B_{2}\right) L^{\prime}} \frac{d F(y)}{d y}\right|_{y=1}>0,\left.\frac{d F(y)}{d y}\right|_{y=0}<0$, so $y=0$ is the evolutionary stability point.

\section{Dynamic Replication Analysis on Employees' Safety Initiative Decision-Making}

The dynamic replication analysis equation of employees' safety initiative decision-making:

$$
F(z)=\frac{d z}{d t}=z\left(V_{1 z}-\bar{V}_{z}\right)=z(1-z)\left\{y\left(a_{1} B_{1} L-a_{2} B_{2} L+A_{1}+A_{2}\right)+a_{2} B_{2} L-A_{2}\right\}
$$

(1) When $y=\frac{A_{2}-a_{2} B_{2} L}{a_{1} B_{1} L-a_{2} B_{2} L+A_{1}+A_{2}}$, let $F(z)=0$, this means that the employees are in a steady state whether to take safety initiative behavior or not.

(2) When $y^{1} \frac{A_{2}-a_{2} B_{2} L}{a_{1} B_{1} L-a_{2} B_{2} L+A_{1}+A_{2}}$, let $F(z)=0, z=0, z=1$ may be the evolutionary stability points. According to the stability theorem of replicated dynamic equation, if $z$ is a stabilization strategy, then $F(z)=0$ and $F^{\prime}(z)<0$. By deriving $F(z)$ :

$$
F^{\prime}(z)=(1-2 z)\left\{y\left(a_{1} B_{!} L-a_{2} B_{2} L+A_{1}+A_{2}\right)+a_{2} B_{2} L-A_{2}\right\}
$$

Under normal circumstances, $a_{1} B_{1} L-a_{2} B_{2} L+A_{1}+A_{2}>0$, there are two cases:

When $y>\frac{A_{2}-a_{2} B_{2} L}{a_{1} B_{1} L-a_{2} B_{2} L+A_{1}+A_{2}},\left.\frac{d F(z)}{d z}\right|_{z=1}<0,\left.\frac{d F(z)}{d z}\right|_{z=0}>0$, so $z=1$ is the evolutionary stability point.

When $y<\frac{A_{2}-a_{2} B_{2} L}{a_{1} B_{1} L-a_{2} B_{2} L+A_{1}+A_{2}},\left.\frac{d F(z)}{d z}\right|_{z=1}>0,\left.\frac{d F(z)}{d z}\right|_{z=0}<0$, so $z=0$ is the evolutionary stability point.

\section{Stability Analysis on Strategies Evolution among Government, Coal Mine Enterprises and Employees}

Stability analysis on the strategies evolution among the three stakeholders of government, enterprises and employees is carried out, namely the evolutionary stability analysis on government and coal mining enterprises, evolutionary stability analysis on coal mining enterprises and employees.

\section{Evolutionary stability analysis on government and coal mining enterprises}

From formulas (1) and (3) we can see that the dynamic game between government and coal mining enterprises contains five equilibrium points: $(0,0),(0,1),(1,0),(1,1),\left(x^{*}=\frac{C_{2}-S-z\left[a_{1}\left(1-B_{1}\right) L-a_{2}\left(1-B_{2}\right) L\right]}{M}, y^{*}=\frac{M-C_{1}+W}{M}\right)$, if and only if $0 \leq \frac{C_{2}-S-z\left[a_{1}\left(1-B_{1}\right) L-a_{2}\left(1-B_{2}\right) L\right]}{M} \leq 1,0 \leq \frac{M-C_{1}+W}{M} \leq 1$, the dynamic game evolution is provided.

Jacobi matrix:

$$
J_{1}=\left[\begin{array}{cc}
(2 x-1)\left[M y-\left(M-C_{1}+W\right)\right] & M x(1-x) \\
M y(1-y) & (1-2 y)\left\{z\left[a_{1}\left(1-B_{1}\right) L-a_{2}\left(1-B_{2}\right) L\right]-\left(C_{2}-S-M x\right)\right\}
\end{array}\right]
$$

Matrix $J_{1}$ determinant:

$$
\begin{gathered}
\operatorname{det}_{1}=(2 x-1)\left[M y-\left(M-C_{1}+W\right)\right](1-2 y)\left\{z\left[a_{1}\left(1-B_{1}\right) L-a_{2}\left(1-B_{2}\right) L\right]-\left(C_{2}-S\right.\right. \\
-M x)\}-M x(x-1) M y(1-y)
\end{gathered}
$$


Table 2. Stability analysis on the evolutionary game between government and coal mine enterprises

\begin{tabular}{ccccc}
\hline Equilibrium point & det $_{\mathbf{1}}$ symbol & trJ $_{\mathbf{1}}$ symbol & Results & Stability condition \\
\hline$x=0, y=0$ & + & + & Unstable point & Unstable under any condition \\
\hline$x=0, y=1$ & + & - & $E E S$ & $C_{1}>W, z\left[a_{1}\left(1-B_{1}\right) L-a_{2}\left(1-B_{2}\right) L\right]>C_{2}-S$ \\
\hline$x=1, y=0$ & + & - & $E E S$ & $z\left[a_{1}\left(1-B_{1}\right) L-a_{2}\left(1-B_{2}\right) L\right]<C_{2}-S-M$ \\
\hline$x=1, y=1$ & + & - & $E E S$ & $C_{1}<W, z\left[a_{1}\left(1-B_{1}\right) L-a_{2}\left(1-B_{2}\right) L\right]>C_{2}-S-M$ \\
\hline$x=x *, y=y *$ & 0 & 0 & Saddle point & A saddle point under any condition \\
\hline
\end{tabular}

Matrix $J_{1}$ trace:

$$
\begin{aligned}
& \operatorname{tr} J_{1}=(2 x-1)\left[M y-\left(M-C_{1}+W\right)\right] \\
&+(1-2 y)\left\{z\left[a_{1}\left(1-B_{1}\right) L-a_{2}\left(1-B_{2}\right) L\right]-\left(C_{2}-S-M x\right)\right\}
\end{aligned}
$$

The local stability analysis is made according to the above five equilibrium points, and the results are shown in Table 2.

As shown in Table 2 that the dynamic evolution process of government and coal mine enterprises can form a stable point while satisfying certain conditions, respectively

1) When the cost of government safety supervision is greater than the social stability benefits, and the safety benefit increase of enterprise transforming from penalty type to incentive type education mode for safety production is greater than the actual cost of transformation, government and enterprises are in a steady gaming state, $x=1, y=0$, namely government does no safety supervision and enterprises take the incentive type education mode for safety production.

2) When the actual increase in safety efficiency after the transformation from the penalty type to the incentive type of education mode for safety production is less than the difference between the actual cost of the mode transformation and the government safety supervision penalty, the game results of government and enterprise are in a stable state, $x=1, y=0$, that is, the government takes safety supervision and enterprise takes the penalty type education mode for safety production.

3) When the cost of government safety supervision is less than the social stability benefits, and the safety benefit increase of enterprise transforming from penalty type to incentive type education mode for safety production is greater than the difference between the actual cost of the mode transformation and the government safety supervision penalty, government and enterprises are in a steady gaming state, $x=1, y=$ 1 , namely government does safety supervision and enterprises take incentive type education mode for safety production.

\section{Evolutionary stability analysis on coal mine enterprises and employees}

As shown in formulas (3) and (5) that the dynamic game between coal mine enterprises and employees contains five equilibrium points: $(0,0),(0,1),(1,0),(1,1),\left(y^{* *}=\frac{A_{2}-a_{2} B_{2} L}{a_{1} B_{2} L-a_{2} B_{2} L+A_{1}+A_{2}}, z^{* *}=\frac{C_{2}-S-M x}{a_{1}\left(1-B_{1}\right) L-a_{2}\left(1-B_{2}\right) L}\right)$, if and only if $0 \leq \frac{A_{2}-a_{2} B_{2} L}{a_{1} B_{1} L-a_{2} B_{2} L+A_{1}+A_{2}} \leq 1,0 \leq \frac{C_{2}-S-M x}{a_{1}\left(1-B_{1}\right) L-a_{2}\left(1-B_{2}\right) L} \leq 1$, the dynamic game evolution is provided.

Jacobi matrix:

$$
J_{2}=\left[\begin{array}{cc}
(1-2 y)\left\{z\left[a_{1}\left(1-B_{1}\right) L-a_{2}\left(1-B_{2}\right) L\right]-\left(C_{2}-S-M x\right)\right\} & y(1-y)\left[a_{1}\left(1-B_{1}\right) L-a_{2}\left(1-B_{2}\right) L\right] \\
z(1-z)\left(a_{1} B_{1} L-a_{2} B_{2} L+A_{1}+A_{2}\right) & (1-2 z)\left\{y\left(a_{1} B_{1} L-a_{2} B_{2} L+A_{1}+A_{2}\right)+\left(a_{2} B_{2} L-A_{2}\right)\right\}
\end{array}\right]
$$

Matrix $J_{2}$ determinant:

$$
\begin{aligned}
\operatorname{det}_{2}=(1-2 y)\{ & z \\
- & \left.\left.\left(1-B_{1}\right) a_{1} L-\left(1-B_{2}\right) a_{2} L\right]-\left(C_{2}-S-M x\right)\right\}(1 \\
& -2 z)\left\{y\left(a_{1} L B_{1}-a_{2} L B_{2}+A_{1}+A_{2}\right)+\left(B_{2} a_{2} L-A_{2}\right)\right\} \\
& -y(1-y)\left[\left(1-B_{1}\right) a_{1} L-\left(1-B_{2}\right) a_{2} L\right] z(1-z)\left(a_{1} L B_{1}-a_{2} L_{B_{2}}+A_{1}+A_{2}\right)
\end{aligned}
$$

Matrix $J_{2}$ trace:

$$
\begin{aligned}
\operatorname{tr} J_{2}=(1-2 y)\{z & {\left.\left[\left(1-B_{1}\right) a_{1} L-\left(1-B_{2}\right) a_{2} L\right]-\left(C_{2}-S-M x\right)\right\} } \\
+ & (1-2 z)\left\{y\left(a_{1} L B_{1}-a_{2} L B_{2}+A_{1}+A_{2}\right)+\left(B_{2} a_{2} L-A_{2}\right)\right\}
\end{aligned}
$$

The local stability analysis is made according to the above five equilibrium points, and the results are shown in Table 3. 
Table 3. Stability analysis on the evolutionary game between coal mine enterprises and employees

\begin{tabular}{ccccc}
\hline Equilibrium point & $\boldsymbol{d e t}_{\mathbf{2}}$ symbol & $\boldsymbol{t r J}_{\mathbf{2}}$ symbol & Results & Stability condition \\
\hline$y=0, z=0$ & + & - & $E E S$ & $M x<C_{2}-S, A_{2}>a_{2} B_{2} L$ \\
\hline$y=0, z=1$ & + & - & $E E S$ & $M x<C_{2}-S-\left[a_{1}\left(1-B_{1}\right) L-a_{2}\left(1-B_{2}\right) L\right], A_{2}<a_{2} B_{2} L$, \\
\hline$y=1, z=0$ & + & + & Unstable & Unstable under any condition \\
\hline$y=1, z=1$ & + & - & $E E S$ & $M x>C_{2}-S-\left[a_{1}\left(1-B_{1}\right) L-a_{2}\left(1-B_{2}\right) L\right], A_{2}<a_{2} L B_{2}$ \\
\hline$y=y * *, z=z * *$ & 0 & 0 & Saddle point & A saddle point under any condition
\end{tabular}

As shown in Table 3 that the dynamic evolution process of government and coal mine enterprises can form a stable point while satisfying certain conditions, respectively

1) When the mathematical expectation of fines to be paid as a result of the penalty type education mode for safety production is less than the actual cost of the mode transformation, and the negative psychological effect obtained by the employee to take the safety initiative is greater than the safety benefits, the enterprise and the employee's game result are in a stable state, $y=0, z=0$, that is, the enterprise takes the penalty type education mode for safety production, employees do not implement security initiatives.

2) When the mathematical expectation of fines to be paid as a result of the penalty type education mode for safety production is less than the difference between the actual input of the mode transformation and the increase of the safety effect after the mode transformation. At the same time, if the negative psychological effect obtained by the employee's safety initiative behavior is less than the safety benefits, the enterprise and the employee's game result are in a stable state, $y=0, z=1$, that is, the enterprise takes the penalty type education mode for safety production, employees implement security initiative behavior.

3) When the mathematical expectation of fines to be paid as a result of the penalty type education mode for safety production is greater than the difference between the actual input of the mode transformation and the increase of the safety effect after the mode transformation. At the same time, if the negative psychological effect obtained by the employee's safety initiative behavior is less than the safety benefits, the enterprise and the employee's game result are in a stable state, $y=1, z=1$, that is, the enterprise takes the incentive type education mode for safety production, employees implement security initiative behavior.

\section{NUMERICAL EXPERIMENT AND SIMULATION}

In this study, starting from the human-oriented education thought, it promotes the final evolution of three party game of government, enterprise and employee into the ideal decision-making state of government safety supervision, enterprise incentive type education mode for safety production and employee safety initiative $(x=$ $1, y=1, z=1)$.

Through the stepwise analysis on the stability of the evolution between coal mining enterprises and employees and between government and coal mining enterprises, we can see that, the evolutionary equilibrium state of government and coal mining enterprises, enterprises and employees is affected by the proportion of employees' safety initiative decision-making ratio decision-making ratio $z$ and government safety supervision decision-making ratio $x$.

The evolutionary stable state analysis on government and coal mining enterprises is: At the point $x=1, y=0$, the stability condition is $z\left[\left(1-B_{1}\right) a_{1} L-\left(1-B_{2}\right) a_{2} L\right]<C_{2}-S-M$, at the point $x=1, y=1$, the stability condition is $z\left[\left(1-B_{1}\right) a_{1} L-\left(1-B_{2}\right) a_{2} L\right]>C_{2}-S-M, C_{1}<W$, as long as $C_{1}<W, x$ is approaching $x=1$. From the stability state analysis on the evolution of government and coal mining enterprises, at the point $y=1, z=1$, the stability condition is $M x>C_{2}-S-\left[\left(1-B_{1}\right) a_{1} L-\left(1-B_{2}\right) a_{2} L\right], A_{2}<a_{2} L B_{2}$. According to the above content and the actual conditions, it can be inferred by the increasing constraints that, when $C_{1}<W, M x>C_{2}-S-\left[\left(1-B_{1}\right) a_{1} L-\right.$ $\left.\left(1-B_{2}\right) a_{2} L\right], A_{2}<a_{2} L B_{2}, a_{1}>a_{2}, B_{1}>B_{2},\left(1-B_{1}\right) a_{1} L-\left(1-B_{2}\right) a_{2} L$, government safety supervision, enterprise's the incentive type education mode for safety production, employees' safety initiative behavior can achieve the desired decision state $(x=1, y=1, z=1)$. According to the constraints and replicated dynamic equation and by using MATLAB simulation software, a numerical analysis on the government, game's ideal state of enterprise and employees is conducted. According to the constraint condition, the parameter values are $W=35, C_{1}=30, C_{2}=28$, $S=10, B_{1}=0.7, B_{2}=0.3, a_{1}=10, a_{2}=2, L=10, M=50, A_{1}=8, A_{2}=5$.

(1) The impact of three-party decision-making ratio on the evolutionary process. The initial ratio is $x_{0}=0.1$, $y_{0}=0.2, z_{0}=0.2 ; x_{0}=0.3, y_{0}=0.4, z_{0}=0.5 ; x_{0}=0.3, y_{0}=0.5, z_{0}=0.7$, from Figure 1, convergence rate of strategy portfolio with a relatively higher decision-making ratio is faster than that of the relatively low strategy portfolio. 


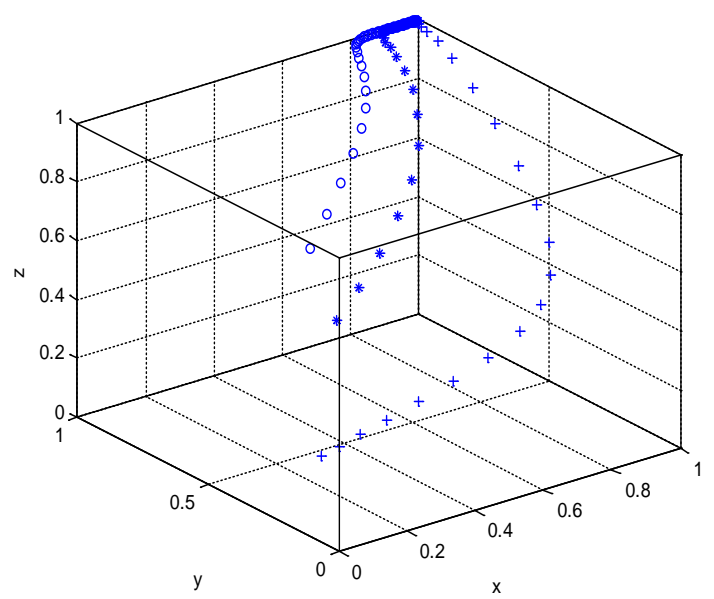

Figure 1. The impact of strategy portfolio of three-party different initial proportions on evolutionary path

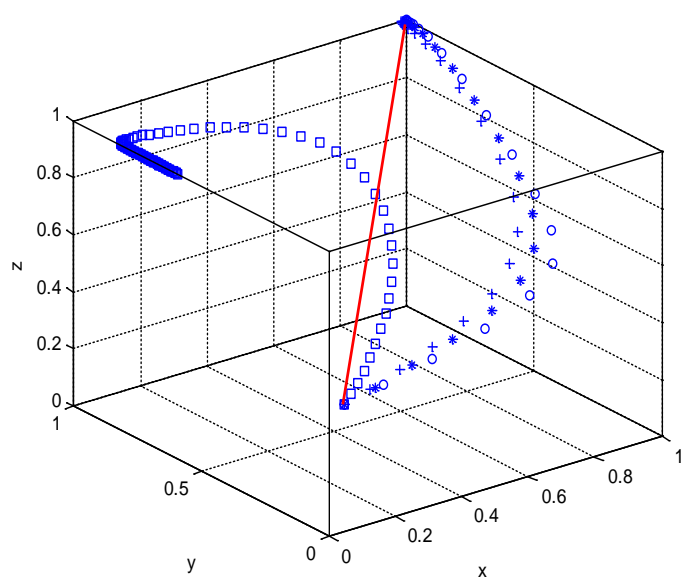

Figure 2. The impact of changes of government input safety supervision cost on evolutionary path

(2) The impact of government input of safety supervision on the evolution process. For example, when $x_{0}=$ $0.2, y_{0}=0.2, z_{0}=0.3$, the safety rate cost $C_{1}$ increases gradually, from Figure 2, it will slow down the evolution speed towards the three-party ideal state, extra high government safety supervision will fail evolve into an ideal state.

(3) The impact of the input cost of incentive type education mode for safety production transformation on the evolution process. For example, when $x_{0}=0.2, y_{0}=0.2, z_{0}=0.3$, the input $\operatorname{cost} C_{2}$ of mode transformation gradually increases, from Figure 2, the increase in input costs will slow down the speed of the three parties' evolution to the ideal state, if the transformation cost is too high and the three parties cannot evolve into an ideal state.

(4) The impact of the government penalty on the evolution process. For example, when $x_{0}=0.2, y_{0}=0.2, z_{0}=$ 0.3 , the amount of government penalty $M$ gradually increases, from Figure 4, the amount of government penalty is too small and not enough, hence cannot effectively drive the enterprise to achieve transformation of education mode for safety production, eventually leading the three parties fail to reach the ideal state. With the increase in the government penalty amount in a certain range, it will speed up the three parties moving towards an ideal state. If the government penalty is too high, companies will produce confrontation psychology, significantly reducing three parties in approaching the ideal state. 


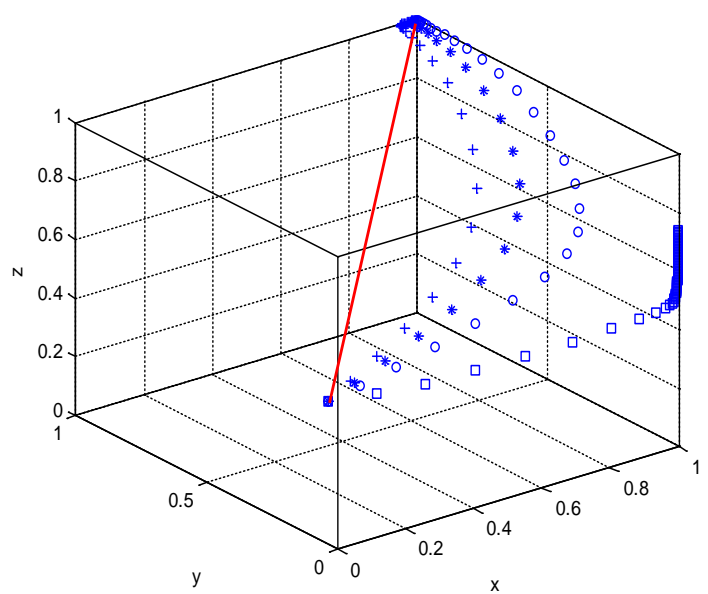

Figure 3. The impact of changes of enterprise mode transformation cost on evolutionary path

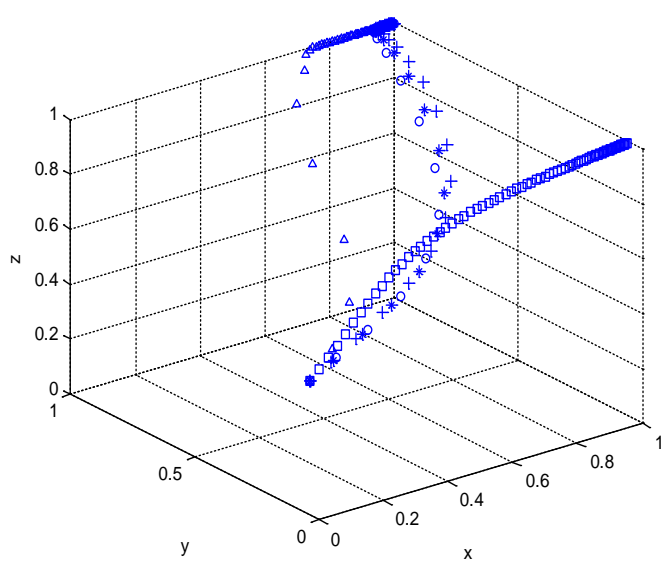

Figure 4. The impact of changes of government penalty on the evolutionary path

(5) The impact of the opportunity cost of the transformation to incentive type education mode for safety production on the evolutionary process, for example, when $x_{0}=0.2, y_{0}=0.2, z_{0}=0.3$, the opportunity cost $S$ gradually increases. From Figure 5, the increase of the opportunity cost of the transformation to incentive type education mode for safety production will speed up the three parties evolve to the ideal state, but the opportunity cost of the enterprise will exceed a certain value, the enterprise will be slack and the evolution speed to the ideal state will slow down.

(6) The impact of positive psychological effects of employees' safety initiative behavior on the evolutionary process. For example, when $x_{0}=0.2, y_{0}=0.2, z_{0}=0.3$, positive psychological effect value $A_{1}$ gradually increases, from Figure 6, positive psychological effect is small, which will reduce the enthusiasm of employees to implement safety initiative behavior; when the positive psychological effect is in a moderate range, positive psychological effect increases, promoting the three parties to evolve to an ideal state; when the positive psychological effect is too large, employees' safety initiative behavior reduces correspondingly, although the three parties can finally reach the ideal state, employees' safety initiative behavior will reduce after a period of time, followed by three parties' detach from the ideal state, as shown in Figure 7. 


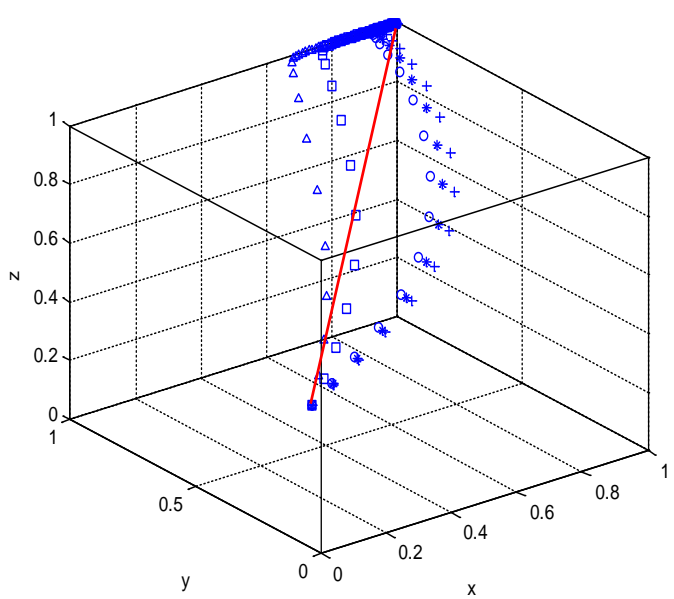

Figure 5. The impact of changes of mode transformation obtain opportunity cost on the evolutionary path

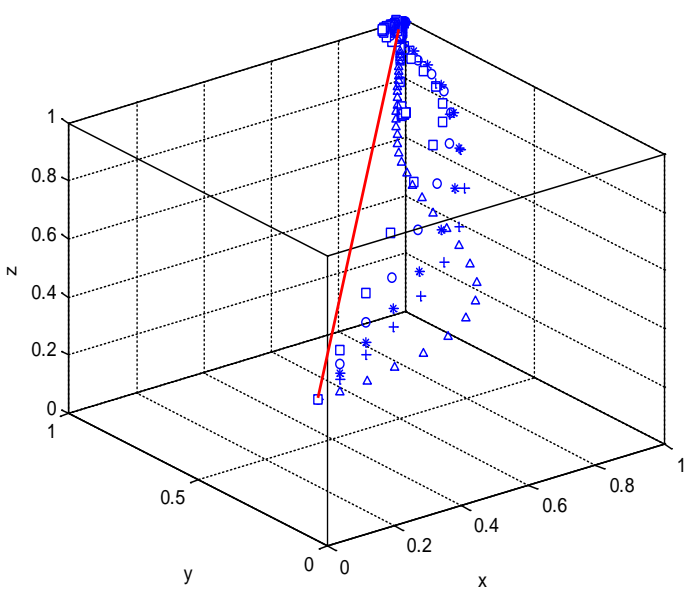

Figure 6. The impact of positive psychological effects of employees' safety initiative behavior on the evolutionary path

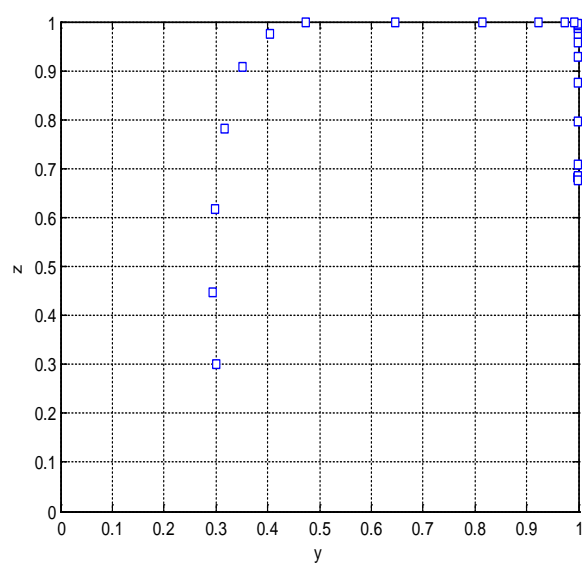

Figure 7. $Y Z$ plane projection

(7) The impact of negative psychological effects of employees' safety initiative behavior on the evolutionary path. For example, when $x_{0}=0.2, y_{0}=0.2, z_{0}=0.3$, the negative psychological effect value $A_{2}$ gradually increases, from Figure 8, when the negative psychological effect is small, it suppresses the three parties to evolve to the ideal state; when the negative psychological effect of employees' safety initiative behavior is too much, employees' safety initiative behavior reduces, hence the three parties cannot reach the ideal state. 


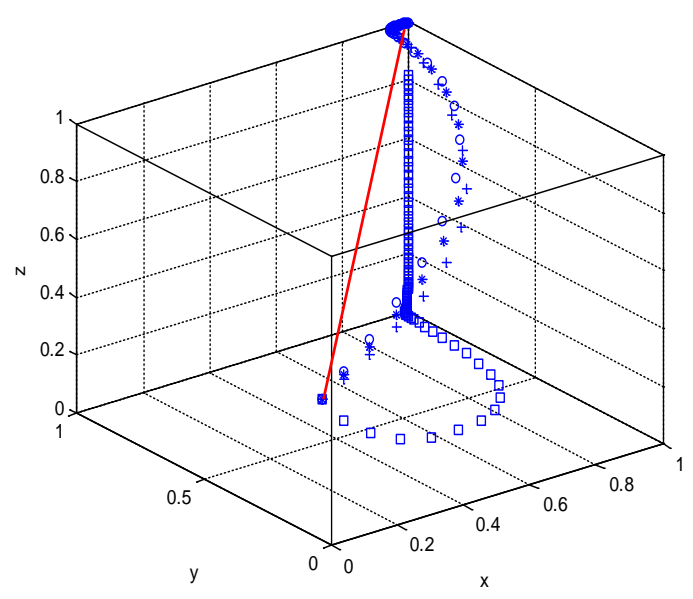

Figure 8. The impact of negative psychological effects of employees' safety initiative behavior on the evolutionary path

\section{DISCUSSION AND CONCLUSION}

\section{Discussion}

Through the decision-making dynamic replication analysis, evolution stability analysis and numerical simulation experiments among the three stakeholders in safety education of the government, coal mine enterprises and employees, the paper consists of the following three parts:

(1) From the dynamic replication equation of the decision-making, the proportion of decision-making under the government safety supervision is related to the proportion of decision-making in the incentive type education mode for safety production by coal mine enterprises, the proportion of decision-making in coal mine enterprises adopting incentive type education mode for safety production is related to the proportion of government decision-making on safety supervision and the proportion of employees' safety initiative, the proportion of decision-making for employees' safety initiative is related to the proportion of decisionmaking in coal mine enterprises adopting incentive type education mode for safety production. Specifically, whether the government decides to adopt the safety supervision decision will be directly affected by whether the enterprise adopts the incentive education mode for safety production instead of whether the employees take safety initiative behavior. Whether the coal mine enterprise decides the safety supervision is influenced by whether the enterprise adopts the incentive type education mode for safety production and whether the employees take safety initiative. Whether employees take safety initiative behavior will be directly affected by whether the enterprise adopt incentive education mode of safety production. The above shows that both government decision-making and employee decision-making are affected by unilateral factors. The bridge among the three parties of government, enterprise and staff is the enterprise. Enterprise decision-making is influenced by both government and employee decision-making. In the process of safety production education, it is necessary to make clear the influence relationship among the three.

(2) From the analysis on evolution stability, we can see that there is no stable state between the government and the coal mine enterprises under any conditions, that is, the government does not adopt the safety supervision strategy, and the enterprise adopts the penalty type education mode for safety production, in other words, this situation does not meet the needs of the actual situation. In addition, there is no stable state if the enterprise adopts incentive type education mode for safety production but employees fail to perform safety initiative behavior. It shows that certain safety supervision from the government is necessary when the enterprise adopts incentive type education mode for safety production, otherwise, they are lack of the driving force to transform education mode for safety production. Enterprises should realize that incentive type education mode for safety production is an effective driving factor for employees to take safety initiative. In addition, when three conditions are satisfied, the three parties can achieve the ideal state: (1) the cost of government safety supervision is less than the benefit from social stability of the government by safety supervision. (2) the mathematical expectation of fine to be paid in the penalty type education mode for safety production is greater than the difference between the actual input of safety education mode and the increment of safety effect after transformation. (3) Employees' safety initiative behavior is negatively affected by psychological effects, which is less than their safety benefits. Three stakeholders of the 
government, the coal mine enterprises and employees can achieve the ideal condition that is, the ideal safety production state of the ideal safety production state of government adopting positive safety supervision, enterprise carrying out the incentive type education mode for safety production, and employees takes safety initiatives.

(3) From the numerical simulation results, we can see that the evolution process of the three parties to the ideal state is affected by many factors: (1) the strategy portfolio with a relatively high initial proportion of three parties converges more quickly to an ideal state than a relatively low strategy portfolio. (2) When the cost of government security supervision is reduced in a certain range, the convergence speed to ideal state can be increased. But when the cost of government safety supervision is too great, the three parties cannot eventually evolve into an ideal state. (3) the increase in enterprise mode transformation cost slows the speed at which three parties evolve to the ideal state. And when the cost of the transformation is too great, the three parties cannot eventually evolve into an ideal state. (4)when the amount of government fines is within a certain range, the increase of the amount will speed up the approaching of the ideal state by three parties. However, if it is less than or greater than this range, three parties cannot achieve the ideal state. (5) the increase in opportunity cost resulting from enterprise mode transformation will speed up the evolution of the three parties to the ideal state. But when the opportunity cost is too large, it slows down the speed of evolution to the ideal state. (6) when positive psychological effects of employees' safety initiative behavior are within a certain range, the positive psychological effects of employees are increased, and the ideal state evolution of the three parties is promoted. However, when the positive psychological effect is too great, the three parties cannot achieve the ideal state. (7) When employees' safety initiative and negative psychological effects is in a certain range, the negative psychological effect of employees increases, and the speed of the evolution of the three parties to the ideal state slows down. However, when the negative psychological effect is too great, the three parties cannot achieve the ideal state.

\section{Conclusion}

Through the evolution analysis on the decision-making behavior of three stakeholders, namely, the government, coal mine enterprises and employees, it is concluded that the cost of government supervision, penalty intensity, supervision efficiency, enterprise and government cooperation, education mode transformation costs, positive or negative psychological effect from employee safety initiative behavior are crucial factors to achieve the ideal decision-making of stakeholders, the conclusions as following:

(1) As a monitor of enterprise safety education, the government can appropriately reduce the cost of safety supervision and increase the penalty, provide reasonable economic and policy support for the transformation of enterprise education mode for safety productions so that enterprises can realize the transition from the penalty type education mode for safety production to the incentive type education mode for safety production. For the government supervision, scientific methods shall be adopted to promote the efficiency of safety supervision. At the same time, it shall be realized that the deterrent effect will decline in case of blindly intensify supervision and penalty, and the game between the government and the enterprise will be more serious. The government can adopt market-oriented means, with the stimulation of economic interests, publicity, guidance and policy support, so as to enable the coal mine enterprises to internalize the goal of improving the production safety education mode, and reverse the passive situation of coal mine enterprises in the reform of safety production education (Martinez, 2016; Pryor, 2016; Millicent et al., 2015). The government and enterprises can use effective safety education to raise employees' awareness and enthusiasm for safety in production, and create a good atmosphere for safety education (Reinhold et al., 2015; Marie et al., 2014).

(2) As the middleman of the three party games, the coal mine enterprises should cooperate with the government and arouse the enthusiasm of the employees, and adopt effective safety education to promote the transformation of the education mode for safety production. The penalty type education mode for safety production shows the impersonal education characteristic, killing the subjective initiative of employees participating in safety production actively, and causing the negative psychology in safety production. The incentive type education mode for safety production stimulates people's initiative, pays attention to the psychological factors of employees, and increases the positive psychological effect of employees through appropriate education and training methods (Moorkamp et al., 2014; Fruhen et al., 2014). The enterprise needs to carry on the essential change to the safe production education mode, specifically: (1) In the education philosophy, learning from DuPont safety education mode, "safety first" shall be taken as the enterprise culture, and upstream and upstream safety education concept shall be established (Autenrieth et al., 2016). (2) In the education institution, learning from HSE management system, three factors "health, safety and environment" shall be included in the whole process of safety production management to emphasize the scientific education mode focusing on prevention first, leadership commitment, full 
participation and continuous improvement, so as to embody a complete and integrated management institution (Yoon et al., 2013; Kramer et al., 2017). (3) In the education method, learning from the method of combining system education and Deming circulation in OHSMS management system to make the education methods scientific, standardized and systematic with the self-improvement and self-discipline ability (Kim et al., 2016; Zwetsloot et al., 2011).

(3) Employees are the direct executor of coal mine production, and play a key role in avoiding safety accidents. The enterprise education mode for safety production should fully stimulate the initiative of employees. According to the theory of three element interaction in social cognitive theory, environment influences human behavior and employees are in the environment of enterprise education mode for safety production, the good or bad of the mode directly affects the employees' safety initiative behavior (Hale et al., 2010; Gholami et al., 2015). Under the penalty type education mode for safety production, attentions fail to be paid to the safety initiatives behavior of employees, effective safety education fails to be implemented, and the motivation to implement safety initiative is then reduced, they will not take the initiative to detect security risks, and even security risks will not be seen (Goh and Ali, 2016; Zohar and Lee, 2016). Coal mining companies should be concerned about employees as much as production costs, follow the education concept of guiding people's behavior, establish correct safety ideas, and have a strong sense of safety and a high sense of safety responsibility education, so as to arouse employees' initiatives, formulate incentive education institution to strengthen the psychological consciousness of employees as a master and make employees regard the interests of enterprises as their own interests, and realize the transformation of "To make me safe" to "I want to be safe" (Kadali and Vedagiri, 2016).

In the study, the decision-making behavior evolution path and evolution law of three stakeholders in the safety production education of government, coal mine enterprises and employees are revealed, and the stable conditions for the main decision to reach the ideal state are found out. The simulation is carried out to provide theoretical reference and practical guidance for the government safety supervision decision-making, enterprise safety education mode transformation and employee safety initiative motivation. Next, combined with the classic paradigm of cognitive neuroscience, using event-related potential technology, the research will focus on further experiment verification of the evolution of the decision-making behavior of the government, coal mine enterprises and employees to make the verification process and result more objective, scientific and referential.

\section{ACKNOWLEDGEMENTS}

The National Social Science Fund of China "Analysis on Evolution and Innovation of Agricultural Production Organization Mode in China Based on Rural Land Transfer on Large Scale", project number 16CJY053.

University Nursing Program for Young Scholars with Creative Talents in Heilongjiang Province "Study on Mechanism and Policy of Promoting Rural Land Transfer and Increasing Farmers 'Income in Major Grain Producing Areas-Taking Heilongjiang Province as an Example", project number UNPYSCT-2015013.

Social Science Fund Project of the Ministry of Education “Research on the Mechanism Innovation of Rural Land Transfer and Its Efficiency \& Income Distribution, project number 14YJC790125.

Philosophy and Social Science Project of Heilongjiang Province "Policy Combination and Supporting Measures of Rural Land Transfer, project number 14B115.

\section{REFERENCES}

Aryee, S., \& Hsiung, H. H. (2016). Regulatory focus and safety outcomes: An examination of the mediating influence of safety behavior. Safety Science, 86(7), 27-35.

Autenrieth, D. A., Brazile, W. J., Sandfort, D. R., Douphrate, D. I., Román-Muñiz, I. N., Reynolds, S. J. (2016). The associations between occupational health and safety management system programming level and prior injury and illness rates in the U.S. dairy industry. Safety Science, 84(7), 108-116.

Cao, Q. G., Li, K., Liu, Y. J., Sun, Q. H., \& Zhang, J. (2012). Risk management and workers' safety behavior control in coal mine. Safety Science, 25(4), 909-913.

Chen, H., Feng, Q., Long, R. Y., \& Qi, H. (2013). Focusing on coal miners' occupational disease issues: A comparative analysis between China and the United States. Safety Science, 51(1), 217-222.

Chen, S. S., Xu, J. H., \& Fan, Y. (2015). Evaluating the effect of coal mine safety supervision system policy in China's coal mining industry: A two-phase analysis. Resources Policy, 46(2), 12-21.

Chin, P., DeLuca, C., Poth, C., Chadwick, I., Hutchinson, N., \& Munby, H. (2010). Enabling youth to advocate for workplace safety. Safety Science, 48(5), 570-579. 
DeArmonda, S., Smith, A. E., Wilson, C. L., Chen, P. Y., \& Cigularov, K. P. (2011). Individual safety performance in the construction industry: Development and validation of two short scales. Accident Analysis and Preven, 43(3), 948-954.

Feng, Q., \& Chen, H. (2013). The safety-level gap between China and the US in view of the interaction between coal production and safety management. Safety Science, 54(4), 80-86.

Fernández-Muñiz, B., Montes-Peón, J. M., \& Vázquez-Ordás, C. J. (2007). Safety culture: Analysis of the causal relationships between its key dimensions. Journal of safety research, 38(6), 627-641.

Fruhen, L. S., Mearns, K. J., Flin, R., \& Kirwan, B. (2014). Skills, knowledge and senior managers' demonstrations of safety commitment. Safety Science, 69(12), 29-36.

Gholami, P. S., Nassiri, P., Yarahmadi, R., Hamidi, A., \& Mirkazemi, R. (2015). Assessment of Health Safety and Environment Management System function in contracting companies of one of the petro-chemistry industries in Iran, a case study. Safety Science, 77(8), 42-47.

Goh, Y. M., Ali, M. J. A. (2016). A hybrid simulation approach for integrating safety behavior into construction planning: An earthmoving case study. Accident Analysis E Prevention, 93(8), 310-318.

Hal, A. R., Guldenmund, F. W., van Loenhout, P. L. C. H., \& Oh, J. I. H. (2010). Evaluating safety management and culture interventions to improve safety: Effective intervention strategies. Safety Science, 48(8), 1026-1035.

Jiang, L., Yu, G., Li, Y. J., \& Li, F. (2010). Perceived colleagues 'safety knowledge/behavior and safety performance: safety climate as a moderator in a multilevel study. Accident analysis E Prevention, 42(5), 1468-1476.

Kadali, B. R., \& Vedagiri, P. (2016). Proactive pedestrian safety evaluation at unprotected mid-block crosswalk locations under mixed traffic conditions. Safety Science, 89(11), 94-105.

Kim, Y. H., Park, J. S., \& Park, M. J. (2016). Creating a Culture of Prevention in Occupational Safety and Health Practice. Safety and Health at Work, 7(2), 89-96.

Kramer, D. M., Haynes, E., Holness, D. L., Strahlendorf, P., Kushner, R., \& Tenkate, T. (2017). Sun Safety at Work Canada: Baseline evaluation of outdoor workplaces recruited to participate in a sun safety knowledge transfer and exchange intervention. Safety Science, 96(7), 172-182.

Krzemień, A., Sánchez, A. S., Fernández, P. R., Zimmermann, K., \& Coto, F. G. (2016). Towards sustainability in underground coal mine closure contexts: A methodology proposal for environmental risk management. Journal of Cleaner Production, 139(12), 1044-1056.

Kumar, P., Gupta, S., Agarwal, M., \& Singh, U. (2016). Categorization and standardization of accidental riskcriticality levels of human error to develop risk and safety management policy. Safety Science, 85(6), 88-98.

Liu, D. H., Xiao, X. Z., Li, H. Y., \& Wang, W. G. (2015). Historical evolution and benefit-cost explanation of periodical fluctuation in coal mine safety supervision: An evolutionary game analysis framework. European Journal of Operational Research, 243(3), 974-984.

Liu, Q. L, Li, X., \& Hassall, M. (2015). Evolutionary game analysis and stability control scenarios of coal mine safety inspection system in China based on system dynamics. Safety Science, 80(12), 13-22.

Marie, L., Ellen, M., \& Bénédicte, C. (2014). Why are occupational health and safety training approaches not effective? Understanding young worker learning processes using an ergonomic lens. Safety Science, 68(10), 250-257.

Martinez, M. A. (2016). Secondary socialization of and ragogical content knowledge: What are the forces at work in an oil and gas safety training conference? Safety Science, 85(6), 220-229.

Martin-Gutierrez, J. (2017). Editorial: Learning Strategies in Engineering Education Using Virtual and Augmented Reality Technologies. Eurasia Journal of Mathematics Science and Technology Education, 13(2SI), 297-300.

McDonald, N., Corrigan, S., \& Daly, C. (2000). Safety management systems and safety culture in aircraft maintenance organizations. Safety Science, 34(1), 151-176.

Millicent, A. A., Richard, A. G., \& Owusu, A. (2015). Traffic safety violations in relation to drivers' educational attainment, training and experience in Kumasi, Ghana. Safety Science, 75(6), 156-162.

Moorkamp, M., Kramer, E. H., Gulijk, C. V., \& Ale, B. (2014). Safety management theory and the expeditionary organization: A critical theoretical reflection. Safety Science, 69(12), 71-81.

Neal, A., Griffin, M. A., \& Hart, P. M. (2000). The impact of organizational climate on safety climate and individual behavior. Safety Science, 34(1-3), 99-109.

Perdomo-Diaz, J., Felmer, P., Randolph, V., \& Gonzalez, G. (2017). Problem Solving as a Professional Development Strategy for Teachers: A Case Study with Fractions. Eurasia Journal of Mathematics Science and Technology Education, 13(3), 987-999. 
Pousette, A., Larsson, S., \& Törner, M. (2008). Safety climate cross-validation, strength and prediction of safety behavior. Safety Science, 46, 398-404.

Pryor, P. (2016). Accredited OHS professional education: A step change for OHS capability. Safety Science, 81(1), 512.

Reinhold, K., Siirak, V., \& Tint, P. (2015). The Development of Higher Education in Occupational Health and Safety in Estonia and Selected EU Countries, Procedia. Social and Behavioral Sciences, 143(8), 52-56.

Smith, N. D., Eldridge, F., \& DeJoy, D. M. (2016). Safety-specific transformational and passive leadership influences on firefighter safety climate perceptions and safety behavior outcomes. Safety Science, 86(7), 92-97.

Torres, F., Neira Tovar, L.A., \& Sylvia Del Rio, M. (2017). A Learning Evaluation for an Immersive Virtual Laboratory for Technical Training applied into a Welding Workshop. Eurasia Journal of Mathematics Science and Technology Education, 13(2SI), 521-532.

Vinodkumar, M. N., \& Bhasi, M. (2011).A study on the impact of management system certification on safety management. Safety Science, 49(3), 498-507.

Wang, L. K., Ni, B. S., Zhang, J. B., Su, X. Q., \& Hu, S. T. (2016). Study on coal mine macro, meso and micro safety management system. Perspectives in Science, 7(3), 266-271.

Wang, Q. X., Wang, H. Q., \& Zuo, Q. (2016). An application of nonlinear fuzzy analytic hierarchy process in safety evaluation of coal mine. Safety Science, 86(7), 78-87.

Wei, J., Chen, H., \& Qi, H. (2015). Who reports low safety commitment levels? An investigation based on Chinese coal miners. Safety Science, 80(12), 178-188.

Yoon, S. J., Lin, H. K., Chen, G., Yi, S., Choi, J., \& Zhen, H. R. (2013). Effect of Occupational Health and Safety Management System on Work-Related Accident Rate and Differences of Occupational Health and Safety Management System Awareness between Managers in South Korea's Construction Industry. Safety and Health at Work, 4(4), 201-209.

Zhang, P., Peterson, S., Neilans, D., Wade, S., McGrady, R., \& Pugh, J. (2016). Geotechnical risk management to prevent coal outburst in room-and-pillar mining. International Journal of Mining Science and Technology, 26(1), 9-18.

Zhang, R. L., Wang, Z. J., \& Chen, J. W. (2012). Experimental research on the variational characteristics of vertical stress of soft coal seam in front of mining face. Safety Science, 50(4), 723-727.

Zohar, D., \& Lee, J. (2016). Testing the effects of safety climate and disruptive children behavior on school bus drivers performance: A multilevel model. Accident Analysis \& Prevention, 95(10), 116-124.

Zwetsloot, G. I. J. M., Hale, A., \& Zwanikken, S. (2011). Regulatory risk control through mandatory occupational safety and health (OSH) certification and testing regimes (CTRs). Safety Science, 49(7), 995-1006.

\section{http://www.ejmste.com}

